\title{
Public Acceptance of Human-Caused Climate Change Is Gradually Rising
}

Lawrence C. Hamilton

$\mathrm{H}$ ave recent extreme weather events in the United States shifted public opinion on climate change? In late summer and fall 2017, disaster headlines were common. Hurricanes caused damage along the Gulf Coast, and brought devastation to Puerto Rico and the Virgin Islands. The West experienced severe wildfires, with 2 million acres aflame at one point. Although attributing particular events to climate change is difficult, scientists have noted that such extremes are becoming increasingly frequent as climate warms. ${ }^{1}$

The graph tracks 36 nationwide and New Hampshire surveys since 2010 that all asked the same climate question. ${ }^{2}$ Over this period, the percentage who say that climate change is happening now, caused mainly by human activities, rose gradually from low50s to mid-60s. ${ }^{3}$ In October, a New Hampshire survey reached 68 percent. That appears consistent with extreme-weather effects-but it is too soon to know whether it will last. As the graph shows, in previous years, climate views did not respond quickly to events, but they have been drifting slowly upwards. ${ }^{4}$

\section{PERCENTAGE AGREEING THAT CLIMATE CHANGE IS HAPPENING NOW, CAUSED MAINLY BY HUMAN ACTIVITIES (SHOWN WITH SOME CLIMATE-RELATED EVENTS)}

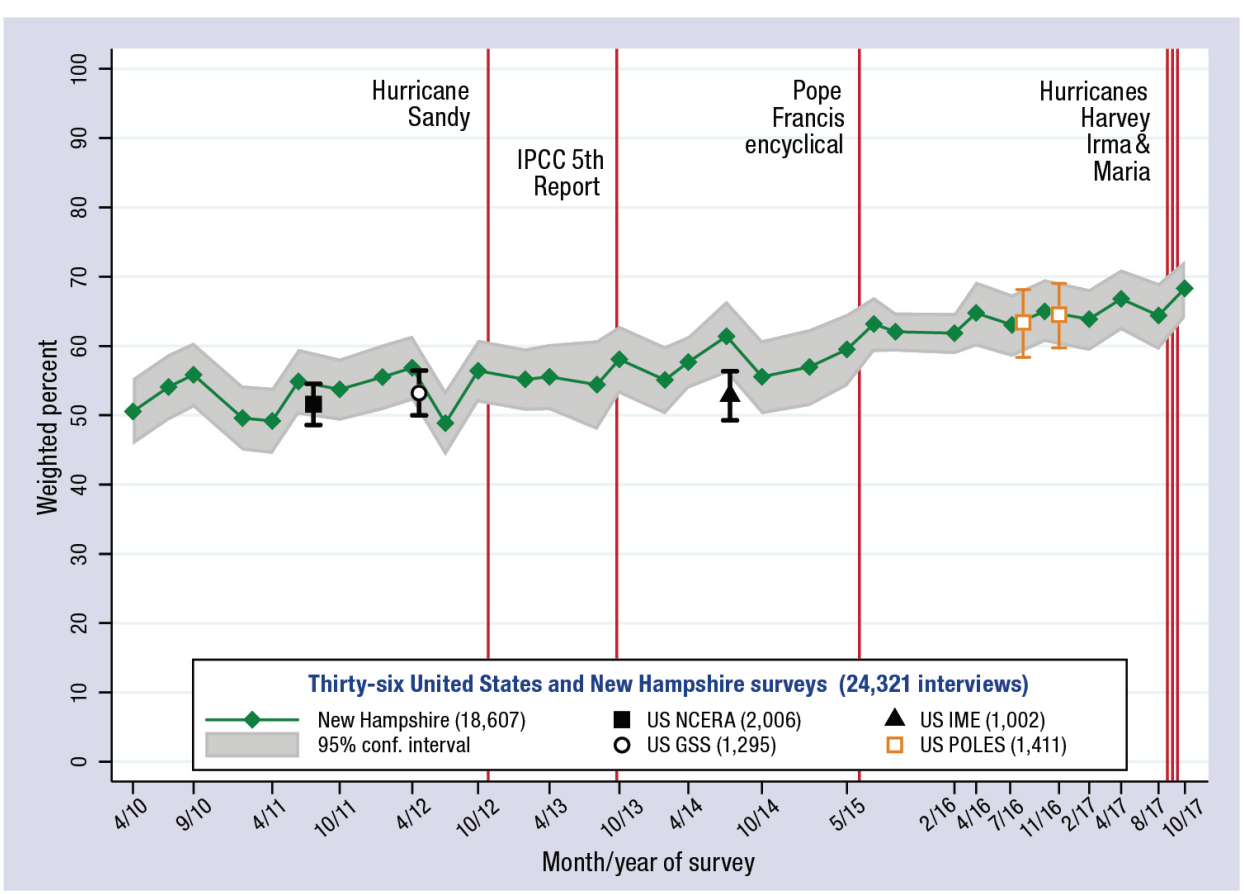

\section{See related publications at carsey.unh.edu}

Eyes Off the Earth? Public Opinion Regarding Climate Science and NASA (June 2017)

- Where Is the North Pole? An Election-Year Survey on Global Change (October 2016)

-Was December Warm? Family, Politics, and Recollections of Weather (June 2016)

\section{Endnotes}

1. U.S. Global Change Research Program, Climate Science Special Report: Fourth National Climate Assessment (NCA4), Volume I (2017), https://science2017. globalchange.gov/.

2. L.C. Hamilton, J. Hartter, M. Lemcke-Stampone, D.W. Moore, and T.G. Safford,"'Tracking public beliefs about anthropogenic climate change," PLOS ONE 10(9) (2015): e0138208, doi: 10.1371/journal.pone.0138208.

3. L.C. Hamilton, "Where is the North Pole? An electionyear survey on global change." Durham, NH: Carsey School of Public Policy, 2016m, http:// scholars.unh.edu/carsey/285/.

4. L.C. Hamilton, "Public awareness of the scientific consensus on climate," Sage Open, 2016, doi: $10.1177 / 2158244016676296$.

Analysis: Lawrence Hamilton, Carsey School, University of New Hampshire

Data: Granite State Poll, NCERA, IMediaEthics, General Social Survey and POLES 